\title{
DNA Methylation Machinery in the Endometrium and Endometrial Cancer
}

\author{
VERONIKA CAPLAKOVA ${ }^{1}$, EVA BABUSIKOVA ${ }^{1}$, EVA BLAHOVCOVA ${ }^{2}$, \\ TOMAS BALHAREK ${ }^{3}$, MARIA ZELIESKOVA ${ }^{4}$ and JOZEF HATOK ${ }^{1,2}$ \\ ${ }^{1}$ Department of Medical Biochemistry, Jessenius Faculty of Medicine in Martin, \\ Comenius University in Bratislava, Martin, Slovakia; \\ ${ }^{2}$ Biomedical Center, Martin, Slovakia; \\ ${ }^{3}$ Department of Pathological Anatomy and University Hospital, \\ Jessenius Faculty of Medicine in Martin, Comenius University in Bratislava, Martin, Slovakia; \\ ${ }^{4}$ Department of Pediatrics and University Hospital, Jessenius Faculty of Medicine in Martin, \\ Comenius University in Bratislava, Martin, Slovakia
}

\begin{abstract}
During the normal menstrual cycle, endometrial tissue undergoes many biochemical and morphological changes which are under the control of steroid hormone levels. DNA methylation plays a key role in gene expression regulation and influences functional changes in endometrial tissue. Eliminating senescent cells from the functional layer of the endometrium is mediated by apoptotic cell death, which helps maintain cellular homeostasis. Aberrant DNA methylation changes result in deregulation of important apoptotic proteins during endometrial carcinogenesis and thus apoptosis resistance development. Evading apoptosis is still a major problem in the successful treatment of endometrial cancer patients with advanced disease. Despite intensive study of the cancer epigenome, there is missing information about disrupted apoptotic gene regulation in DNA methylation levels. Therefore, it is necessary to spread our knowledge in the field of epigenetics to help us differentiate normal and cancer tissues and detect the early stages of cancer disease.
\end{abstract}

The human endometrium is a hormone-sensitive tissue which undergoes complicated biochemical and morphological

This article is freely accessible online.

Correspondence to: Jozef Hatok, Department of Medical Biochemistry, Jessenius Faculty of Medicine in Martin, Comenius University in Bratislava, Mala Hora 4D, 03601 - Martin, Slovakia. Tel: 00421-43-2633-469, e-mail: hatok@jfmed.uniba.sk

Key Words: DNA methylation, menstrual cycle, endometrial cancer, apoptosis, review. changes accompanied by phases of cell growth, proliferation and cell death. These processes are regulated by ovarian hormone levels and their nuclear receptors. Steroid nuclear receptors are transcription factors which become activated after binding to their ligands and are essential for target gene regulation (1). The nuclear receptors can interact with DNA methylation/demethylation enzymes or other recruited proteins and thus maintain methylated and demethylated states of target genes $(2,3)$. Several studies have described DNA methylation changes during normal menstrual cycle phases and their significance in cell homeostasis of endometrium tissue (4-6).

Abnormalities in the DNA methylation pattern may be associated with implantation failure and early pregnancy loss, as well as other endometrial pathologies and cancer development (7).

Endometrial cancer is now the most common gynaecological malignancy in developed countries. It is the fourth most common cause of death in cancer patients in Europe and North America (8). Despite recent advances made in the treatment and diagnosis of this disease, about 81,500 women are affected every year in the European Union and the incidence is still increasing (9). The risk of endometrial cancer increases with many factors including early onset of menstruation, nulliparity, obesity, diabetes, infertility, late menopause and menopausal oestrogen therapy, all of which are associated with oestrogen exposure (10). Most endometrial malignancies develop in endometrial gland cells and are referred to as endometrioid adenocarcinomas (9). Based on the clinical-pathological and molecular characteristics, endometrial carcinomas have been classified into two groups, called type I (endometrioid endometrial carcinoma, EEC) and type II (non-endometrioid endometrial carcinoma, NEEC). Type I carcinomas are low grade, oestrogen-related tumours that are 
characterized by a favourable prognosis. In contrast, type II carcinomas are unrelated to oestrogen stimulation and occur in older women. They are characterized by an aggressive clinical course and poor prognosis $(11,12)$. Traditional treatment for patients with endometrial cancer is based on surgery, radiation therapy, hormonal therapy and chemotherapy. Surgical resection is the main treatment for women who are diagnosed in early stages of endometrial cancer (13) whereas the standard care for patients with advanced or recurrent disease is still based on using a combination of chemotherapy and radiotherapy.

One of the major goals of cancer therapy is to trigger apoptosis, which is often, in the case of patients with advanced disease, ineffective. Response to therapy is an important factor which favours the prognosis and overall survival of cancer patients; therefore, the major goal of cancer research is to distinguish normal tissue from cancerous or precancerous tissue (13). Apoptosis resistance is one of the most striking hallmarks of cancer, which enables tumour growth and metastatic dissemination and is still a major problem in cancer research (14). Cancer cells have developed numerous strategies of resistance to apoptosis such as genetic mutations and defects in epigenetic modifications (15). Study of epigenetic mechanisms is a very popular and expanding field in biomedical cancer research. Epigenetic changes including DNA methylation, covalent histone modifications, nucleosome positioning and noncoding RNA molecules (miRNAs) (16) are increasingly regarded as key events in the development of endometrial cancer (17). In this review, we will focus on the DNA methylation mechanism and its effects on various genomic regions and function in normal endometrium tissue and the menstrual cycle. We also describe defects in the DNA methylation pattern in endometrial cancer in relation to apoptosis resistance.

\section{DNA methylation-an important epigenetic modification}

Epigenetics was first defined by evolutionary biologist C. H. Waddington as the branch of biology that studies the causal interactions between genes and their products in developmental processes that create a cellular phenotype in response to a given environment (18). The current definition of epigenetics refers to the mitotically and meiotically heritable changes in gene expression that are not caused by alterations in the primary DNA sequence or DNA content and are maintained through multiple cycles of cell division $(16,19)$. Unlike genetic aberrations, epigenetic changes can be induced by environmental factors and are potentially reversible and thus convenient and promising targets in anticancer strategies $(20,21)$.

DNA methylation is the most widely studied epigenetic mechanism which has a crucial role in the regulation of gene activity. This epigenetic modification was the first observed covalent DNA modification, which was discovered earlier than the chemical and physical structure of the DNA molecule. Methylated cytosines were first described by Hotchkins in calf thymus using paper chromatography. He suggested that these modified cytosine residues existed naturally in DNA molecules (22). However, the function of methylated cytosine was unknown for nearly 30 years after this discovery until several studies demonstrated the important role of 5-methylcytosine $(5-\mathrm{mC})$ as an epigenetic modification in regulating gene expression (23).

DNA methylation is a biochemical modification that is crucial for normal development and cellular differentiation. It is essential for silencing retroviral elements, genomic imprinting, $\mathrm{X}$ chromosome inactivation and regulating tissue-specific gene expression. DNA methylation entails addition of a methyl group $(-\mathrm{CH} 3)$ to the 5 position of cytosine residues. This process is catalysed by DNA methyltransferases (DNMT) which transfer the methyl group from $\mathrm{S}$-adenylmethionine to the cytosine residue to form 5$\mathrm{mC}$. This modified base is sometimes referred to as the fifth nucleotide of the human genome, because about $4 \%$ of the cytosine residues in the genome are methylated $(24,25)$.

\section{Location of DNA methylation}

The majority of DNA methylation occurs in cytosines that precede a guanine nucleotide ( $\mathrm{CpG}$ dinucleotide). In the human genome, more than $70-80 \%$ of all cytosine residues are methylated, but the patterns vary between the cell types of the organism (25-27). CpG sites are not randomly distributed in the genome. They can be classified into two different groups in the context of $\mathrm{CpG}$ density and DNA methylation: $\mathrm{CpG}$ poor and $\mathrm{CpG}$ rich regions called $\mathrm{CpG}$ islands. $\mathrm{CpG}$ islands are DNA sequences that are defined as being longer than 500 bp with a $\mathrm{CpG}$ content greater than $55 \%$ (28). In the human genome, there are many different regions where DNA methylation can occur and it may exert different biological influences on gene activity (Figure 1). In the following sections we will describe different genomic regions in relation to DNA methylation and its different influences on gene activity in normal cells compared to cancer cells.

Repetitive and intergenic regions. The human genome consists of approximately $45 \%$ repetitive and viral elements, whose main components are retrotransposons of the SINE (Short Interspersed Nuclear Element) and LINE (Long Interspersed Nuclear Elements) classes and long terminal repeats (LTR) (29). Repetitive elements originate from DNA and RNA viruses and also from our own RNA molecules which have the ability to replicate independently of the host genome and freely move and insert into other genomic regions. The expression of these elements has a potentially 


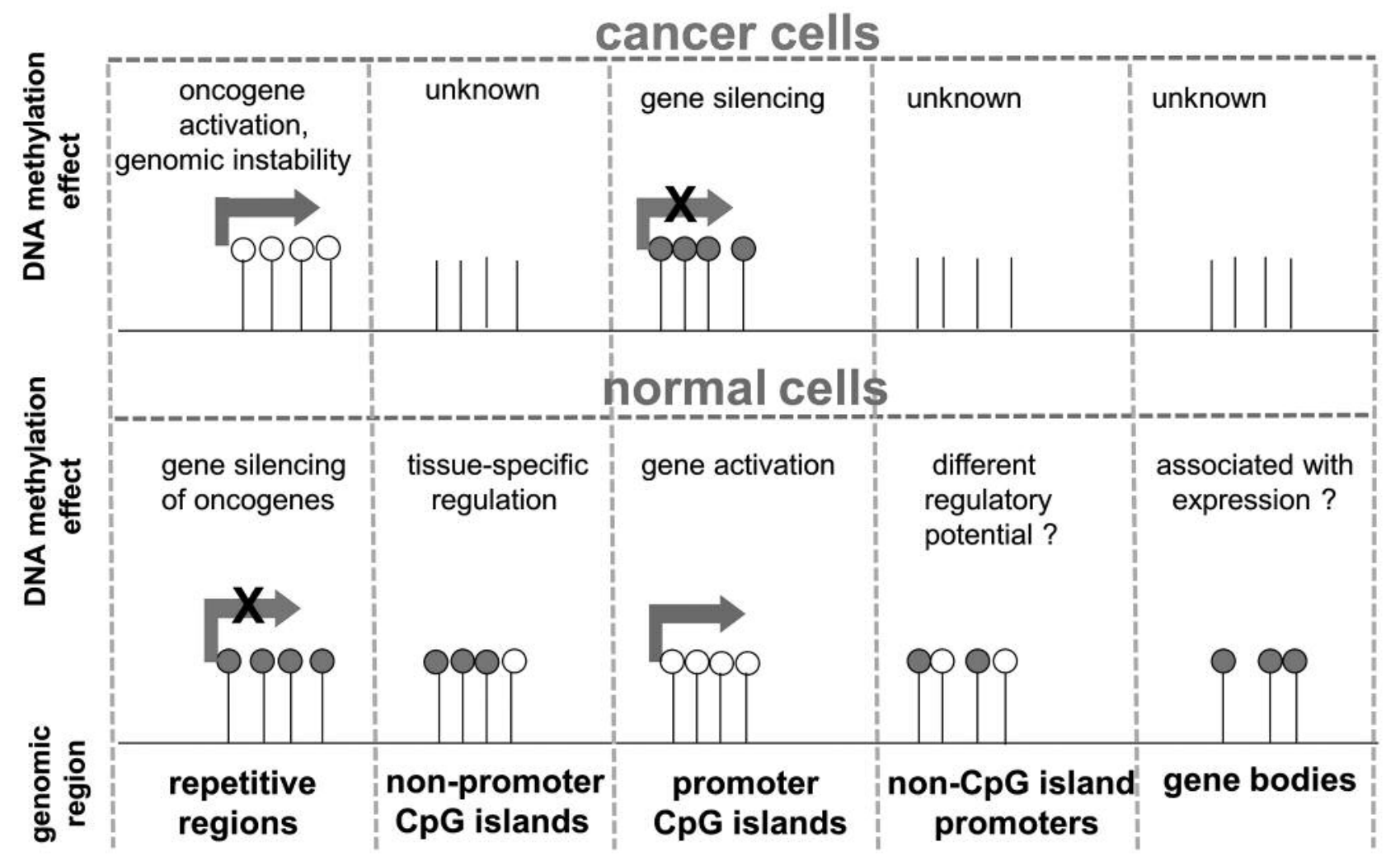

Figure 1. Scheme of DNA methylation effect on different genomic regions in cancer and normal cells. Methylated CpG sites are represented by grey full circles, open circles represent nonmethylated CpG sites. DNA methylation can lead to the gene inactivation (red arrow with black cross) and nonmethylated $\mathrm{Cp} G$ sites can occur in actively transcribed genes (arrow without cross).

harmful effect, because it can lead to gene disruption and DNA mutations, demonstrated by many molecular and evolutionary studies (30-32). Thus, the vast majority of these elements are silenced by DNA methylation to inhibit their expression and protect genome stability. Due to their high coverage of the human genome, many $\mathrm{CpG}$ sites are localized in these compartments (29).

The loss of DNA methylation in intergenic and repetitive genomic regions is an event very often observed in many human cancers such as colon, prostate, liver, endometrium, lung, leukemia (27, 33-39). The cancer genome is characterized by a low level of DNA methylation compared to genomes of normal cells, and this demethylation trend can be increased during cancer development (40). Cancer DNA demethylation in repetitive and intergenic regions is responsible for the increased instability of the genome and the reactivation of mobile elements, especially activation of oncogenes (41-43).

CpG islands. The majority of $\mathrm{CpG}$ islands (nearly 70\%) lie within annotated promoter regions, making these regions the most common promoter type in humans (44). Particularly, promoters of housekeeping genes are often embedded in $\mathrm{CpG}$ islands (45). In general, $\mathrm{CpG}$ islands are localized in positions $-1 \mathrm{~kb}$ to $+0.5 \mathrm{~kb}$ from transcription start sites.

Gene promoters can be divided into two groups, according to occurrence of DNA methylation and $\mathrm{CpG}$ islands: $\mathrm{CpG}$ island promoters and non-CpG island promoters. The main regulatory function of DNA methylation is associated with $\mathrm{CpG}$ islands. In normal and differentiated cells, a great part of $\mathrm{CpG}$ island promoter regions (approximately $94 \%$ ) is not methylated (40). Exceptions include $\mathrm{CpG}$ islands on inactive $\mathrm{X}$-chromosomes in female cells, where they are hypermethylated (46). During embryonic development and differentiation, $\mathrm{CpG}$ islands undergo a DNA methylation process which is important for gene imprinting and tissuespecific gene expression (47). In general, methylated $\mathrm{CpG}$ island promoters result in inhibition of gene transcription or gene silencing (48).

A similar phenomenon is observed in cancer cells, where $\mathrm{CpG}$ island promoters become hypermethylated and are often associated with tumour suppressor genes. Silencing of tumour suppressor genes is a crucial event in the initiation 
of carcinogenesis (40). Hypermethylation of some tumour suppressor genes that function in DNA repair mechanisms or regulating the cell cycle may be considered as a driving force in tumorigenesis (49). For example, epigenetic inactivation of the mismatch repair gene $M L H I$ was demonstrated in many human cancers such as colorectal and endometrial, and it results in downstream genetic mutations and microsatellite instability $(50,51)$.

In contrast, non-CpG island promoters are found methylated in normal cells. It was shown that these genomic regions were methylated in active genes (40). DNA methylation in this promoter type can be associated with different regulatory potential in promoter activity (29). The precise DNA methylation function in gene activity is not well known in these regions. Further studies are needed to determine the function of DNA methylation in non-CpG island promoters.

Non-promoter $\mathrm{CpG}$ islands. $\mathrm{CpG}$ islands are also localized in intragenic or intergenic regions outside promoter regions and they are classed as 'orphan' CpGs, whose function is unknown. In contrast to the rarely methylated $\mathrm{CpG}$ promoter islands, non-promoter $\mathrm{CpG}$ islands are much more highly methylated in normal cells (44). The function of DNA methylation in these regions in normal and cancer cells is not well studied. It is assumed that these $\mathrm{CpG}$ islands may represent distal regulatory regions of unknown transcripts or tissue-specific genes (52).

Gene bodies. The gene body is another genomic compartment that is targeted by DNA methylation. It represents the region of the gene past the first exon. In gene bodies, DNA methylation occurs mainly in exons which are $\mathrm{CpG}$ poor and it is responsible for $\mathrm{C}$ to $\mathrm{T}$ transition mutations in cancer cells (49). DNA methylation in this region was found in actively transcribed genes (53). It disproved the fact that DNA methylation correlates with repression of gene activity (54). It was shown that a significant proportion of gene bodies with $\mathrm{CpG}$ islands exhibit a tissue-specific DNA methylation pattern $(44,52$, 55). The function of DNA methylation in these regions is still not clear. It seems that DNA methylation in actively transcribed genes may be a result of evolutionary steps leading to the differentiation of invertebrate and vertebrate genomic DNA methylation (56). Some studies suggested that gene body DNA methylation may increase transcriptional activity by inhibiting intragenic promoter activity or by blocking the activity of repetitive DNA within the transcriptional unit (52). Another explanation is that DNA methylation may stabilize nucleosome positions at intronexon junctions and thus increase efficiency of transcriptional elongation or splicing (57).

\section{DNA Methylation Machinery}

The mechanism of DNA methylation is established, maintained and erased by many enzymes which can be classified into three classes: writers, erasers and readers (Figure 2). Writers are proteins that modify cytosine residues and establish or maintain a DNA methylation pattern. Erasers remove methylation groups from cytosine residues and readers recognize and bind to methylated $\mathrm{CpG}$ sites to regulate gene activity and chromatin architecture (47). Data obtained from epigenetic studies showed that components of DNA methylation machinery may communicate and interact, but there are many unanswered questions about the mechanisms they use to maintain cell homeostasis.

Writers of DNA methylation. This group comprises DNMT enzymes which modify the 5 position of the cytosine pyrimidine ring and form 5-mC. During the catalytic mechanism, the targeted cytosine is flipped out of the DNA and inserted into the binding pocket of a methyltransferase enzyme. In the active site, cysteine thiolate forms a transition state intermediate with carbon 6 of the cytosine residue and creates a reactive 4,5-enamine which attacks the methyl group provided by the cofactor (58-60).

There are at least five known members of the DNA methyltransferase group (DNMT1, DNMT2, DNMT3A, DNMT3B and DNMT3L) included in three families $(1,2$ and 3). The members of the DNMT1 and DNMT3 families comprise two domains: the $\mathrm{N}$-terminal regulatory domain with various interaction regions and the $\mathrm{C}$-terminal catalytic domain. The members of DNMT2 lack the N-terminal domain. The members of the last group are more similar in size to prokaryotic methyltransferases rather than eukaryotic enzymes (61). Enzymes of the DNMT families have a unique cell localization and expression pattern which can be driven by sex-specific promoters and exons in the 5' region of genes (60).

The DNMT1 family maintains the original DNA methylation pattern. DNMT1 was the first purified and cloned DNMT $(61,62)$. It has been shown that DNMT1 is targeted to replication foci where it has a very high preference for hemimethylated DNA strands and it is associated with DNA replication machinery $(60,63)$. During replication, DNMT1 reproduces the parental DNA methylation pattern in the daughter DNA strands (61).

The DNMT3 family includes three members: DNMT3L, DNMT3A and DNMT3B. The last two enzymes predominantly catalyse de novo methylation which occurs on both unmethylated DNA strands. Enzymes DNMT3A and DNMT3B have similar domain arrangements: a C-terminal catalytic domain and an $\mathrm{N}$-terminal regulatory region. Despite similar homology structures, the enzymes have a different expression profile. The level of DNMT3B is very 


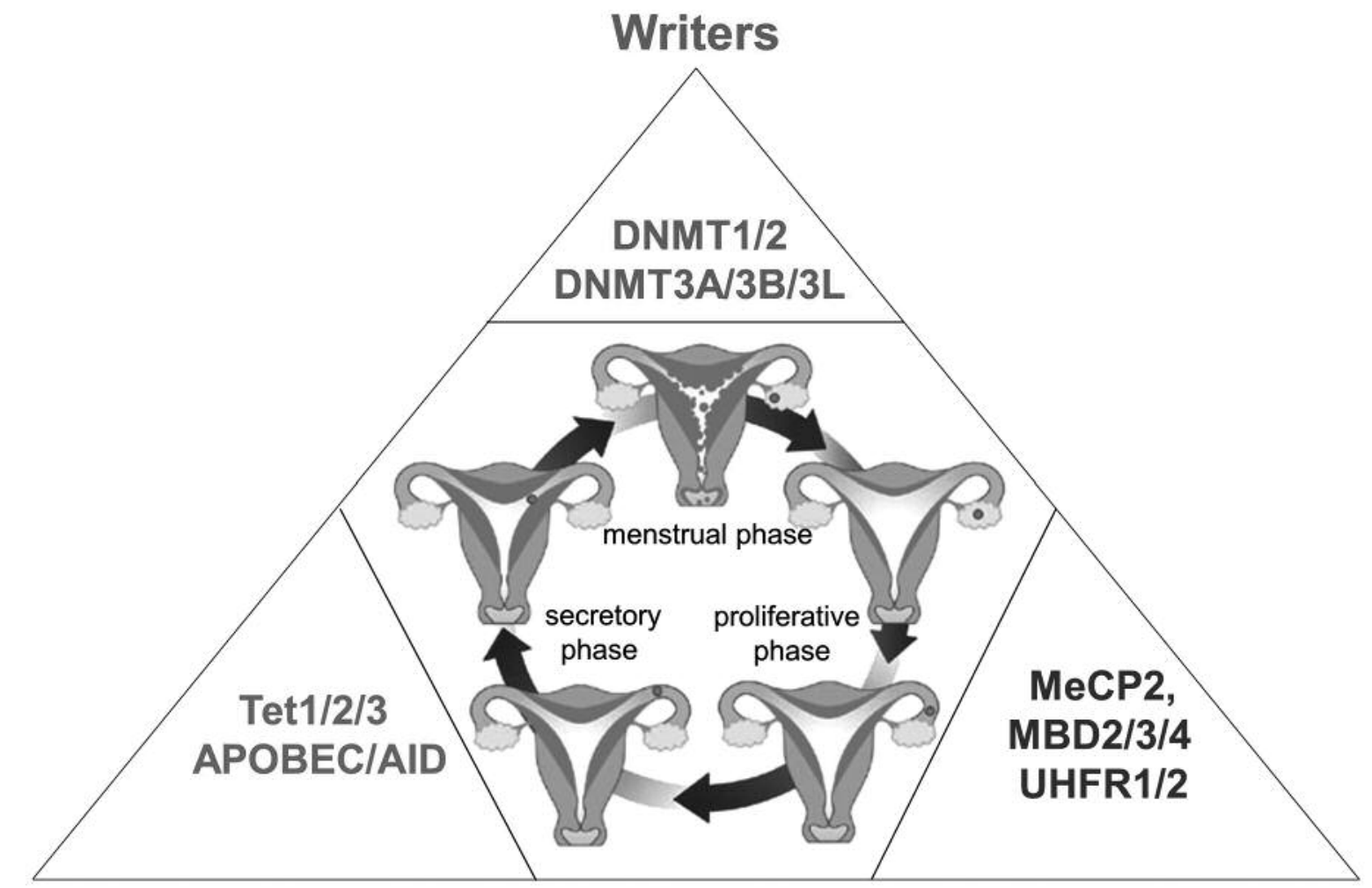

\section{Erasers}

Readers

Figure 2. Components of DNA methylation machinery in relation to the menstrual cycle. The proteins of DNA methylation machinery can be divided into three groups: writers, erasers and readers. These proteins can cooperate all together and regulate gene expression of proteins in menstrual cycle phases.

high in early embryonic development during which it is responsible for methylation of imprinted and repetitive sequences (64), whereas DNMT3A is active mainly in the late phases of embryonic development and cell differentiation $(65,66)$.

DNMT3L has a very similar amino acid sequence to DNMT3A and DNMT3B, but it lacks the conserved residues required for DNMT activity in the C-terminal domain (67). This protein functions as a regulatory factor. It interacts with DNMT3A and DNMT3B enzymes and enhances de novo methylation activity of both enzymes by stabilizing the active catalytic sites in maintenance enzymes $(68,69)$. The protein DNMT3L is expressed specifically in male and female germ cells, where it is essential for the methylation pattern (71).

Enzymes belonging to the DNMT2 family are the most strongly conserved components of the DNMT family. The most important and most widely distributed representative is the DNMT2 protein which more closely resembles bacterial enzymes. The human DNMT2 enzyme is a relatively small protein which lacks the large $\mathrm{N}$-terminal regulatory domain. It is ubiquitously expressed in human tissues (72). Compared to other methyltransferases, DNMT2 is an RNA methyltransferase which can methylate cytosines in the anticodon loop of tRNA $^{\text {ASP }}$ despite its high sequence and structural similarity to other DNMT enzymes. This DNMT2-mediated methylation of tRNA $^{\text {ASP }}$ exhibits a post-transcriptional regulatory role in synthesis of proteins containing poly-Asp sequences (70).

Erasers of DNA methylation (DNA demethylation). The erasing or loss of DNA methylation was the first epigenetic mechanism observed in colon cancer in 1983 (33). DNA methylation can be passively erased due to inhibition of maintenance DNMT, which is involved in sustaining the DNA methylation pattern (73). Although the question about the existence of an active DNA demethylation process was controversial for a long time, nowadays several mechanisms of active DNA demethylation are known.

Modified cytosine residues $(5-\mathrm{mC})$ can chemically react at two sites: the amino group and the methyl group. The amino group can be deaminated to a carbonyl group by the protein AID/APOBEC (activation-induced cytidine deaminase/ 
apolipoprotein B mRNA-editing enzyme complex), which converts 5-mC into thymine and results in a GC to TA transition mutation (74).

Recently discovered was the Tet (ten-eleven translocation) family of enzymes (Tet1, Tet 2 and Tet 3 ) that can mediate the active DNA demethylation process (75). These enzymes modify $5-\mathrm{mC}$ by the addition of a hydroxyl group onto the methyl group to form 5-hydroxymethylcytosine (5-hmC). This modified base can be converted back into cytosine by two different pathways. First, Tet enzymes can further oxidize 5$\mathrm{hmC}$ to 5-formylcytosine (5-fC) and then 5-carboxycytosine (5-caC) (76). In the second chemical pathway, 5-hmC can be deaminated to create 5-hydroxymethyluracil (5-hmU). The products from these active DNA demethylation pathways including 5-fC, 5-caC, 5-hmU and thymine can be recognized and replaced with naked cytosines by base excision repair machinery (BER) (77).

Readers of DNA methylation. DNA methylation can be recognized by a free family of proteins with various DNA binding domains including MBD (methyl-CpG-binding domain) proteins, UHRF (ubiquitin-like, containing PHD and RING finger domain) proteins and zinc finger proteins. Members of the MBD family contain conserved methylCpG-binding domains which selectively recognize methylated $\mathrm{CpG}$ dinucleotides and transcriptional repression domains to provide binding with other repressive complexes (78). The MBD family of proteins plays a key role in gene silencing and includes several members, namely MeCP2, MBD1, MBD2, MBD3 and MBD4 (79-81).

Methylated cytosines are also recognized by the UHRF family of proteins comprising the multidomain proteins UHRF1 and UHRF2. It was demonstrated that UHRF proteins bind to hemimethylated DNA via SET- and RING(a really interesting new gene) associated domains and flip 5-mC out of the DNA helix (82). The protein UHRF1 forms complexes with DNMT1 and targets it to hemimethylated DNA. Studies suggested that UHRF1 is an essential factor for the maintenance of DNA methylation $(83,84)$. This protein can recruit histone-modifying enzymes such as the histone deacetylase HDAC1, histone acetyltransferase Tip60 and lysine histone methyltransferase G9a to maintain local and global DNA methylation and inactive chromatin structure (85). Until now, the same activity for the second member UHRF2 has not been confirmed. It was shown that UHRF2 can bind to DNA depending on the presence of an H3K9 heterochromatin mark, but not DNA methylation (87). Compared with the MBD family of proteins, it seems that UHRF proteins have a function in interaction with DNMT enzymes or other epigenetic regulators to maintain DNA methylation rather than binding to methylated $\mathrm{CpG}$ sites.

The members of the zinc finger family including Kaiso, ZBTB4 (zinc finger and BTB domain-containing 4) and
ZBTB38 (zinc finger and BTB domain-containing 38) bind methylated DNA by their homologous zinc finger domain. The protein Kaiso can recognize a specific consensus sequence without methylated cytosines as well as with methylated CpG dinucleotides (88). Unlike Kaiso, ZBTB4 and ZBTB38 can bind single methylated $\mathrm{CpG}$ dinucleotides. Like the DNMT family of proteins, these proteins are able to repress transcription in a methyl-dependent manner (89).

\section{The Relationship of DNA Methylation to Gene Regulation}

In relation to the previous section, it is not surprising that components of DNA methylation machinery play an important role in activation or repression of transcription, although it is obvious that DNA methylation cooperates with histone modifications and micro RNA molecules to regulate gene expression. This process is dynamic and complex and therefore in the next section we will only briefly describe the importance of DNA methylation and some proteins of DNA methylation machinery in gene expression.

DNA methylation can influence gene regulation by several mechanisms. Methylated cytosines alter the structure of the major groove of DNA and prevent binding of transcription factors to their binding sites and thus inhibit gene transcription. In addition, DNA methylation allows the recruitment of proteins with high affinity for methylated CpG dinucleotides (DNA methyl-binding proteins, MBD) to their target regulatory sites for heterochromatin formation and gene silencing (90). Proteins of the MBD family play a key role in gene repression, because they serve as the strongest link between DNA methylation and histone modifications that establish a transcriptionally inactive chromatin structure (91). The protein MeCP2 represents the major member of the MBD family in transcription repression. It interacts with co-repressor complexes containing histone deacetylases (such as Sin3A) which remove acetyl groups from histones, and histone methyltransferases (HMT) which add methyl groups to histones resulting in chromatin remodelling (92). Furthermore, transcription repression is accompanied by interaction of DNMTs with HMTs. Interactions between DNMT1 and G9a (an HMT) lead to the dimethylation of histone $\mathrm{H} 3$ lysine 9 (H3K9me2), a repressive epigenetic mark. Methylated $\mathrm{H} 3 \mathrm{~K} 9$ is recognized by the adaptor heterochromatin protein HP1 which interacts directly with DNMT1, resulting in cytosine methylation which is recognized by the MBD family of proteins $(93,94)$. DNMT1, DNMT3A and DNMT3B can also interact with other H3K9 methyltransferases (SUV39H1 and ESET) leading to $\mathrm{H} 3 \mathrm{~K} 9 \mathrm{me} 2$, or with polycomb repressive methyltransferase (EZH2) which is responsible for the trimethylation of histone $\mathrm{H} 3$ on lysine 27 (H3K27me3) (92, 
95). Histone marks $\mathrm{H} 3 \mathrm{~K} 9$ and $\mathrm{H} 3 \mathrm{~K} 27$ are important markers of DNA methylation. Thus, epigenetic information embodied in methylation states would flow from histone to DNA and back according to the designated model, for a selfreinforcing cycle of repressed epigenetic states (96).

In contrast, in regions of DNA with active transcription, members of the Tet family of proteins remove DNA methylation marks. Histone tails in these regions often contain trimethylation of histone 3 lysine 4 (H3K4me3) that inhibits DNMT binding to unmethylated $\mathrm{CpG}$ sites and maintains a permissive environment for transcription (47). Despite the DNA demethylation activity of the Tet family of proteins, Tet proteins can associate with corepressor complexes ( $\operatorname{Sin} 3 \mathrm{~A})$ and bind to the promoters of repressed genes and participate in gene activation (97). Therefore, further studies are needed to investigate the precise role of Tet enzymes and their products including 5-hmC, 5-fC and 5 -caC in gene expression.

\section{Menstrual Cycle and DNA Methylation}

The human endometrium is a hormone-sensitive tissue which consists of basal and functional layers. Endometrial tissue in women undergoes cyclic morphological and biochemical changes involving periods of cell regeneration, growth, differentiation, regression and apoptosis with each new menstrual cycle, on average every 28 days. The menstrual cycle is divided into three phases: proliferative, secretory and menstrual phases (98) that are under control of the ovarian steroid hormones oestradiol (E2) and progesterone (P4). They interact with their receptors (oestrogen and progesterone receptors), also known as nuclear transcription factors.

During the proliferative phase, increasing serum oestrogen levels stimulate endometrial growth of epithelial and stromal cells, which is accompanied by higher oestrogen and progesterone receptor levels (99). Unlike the proliferative phase, the secretory phase of the menstrual cycle is under the control of progesterone levels produced by the corpus luteum. This phase starts after ovulation, which occurs around the fourteenth day of the cycle (100), and it ends up with shedding of the functional endometrial layer (menstruation). The basal layer remains intact during the menstrual cycle. It is important for proper function of the functional layer, because it may contain a local population of stem/progenitor cells which can extensively proliferate and differentiate into different cell types and thus contribute to the regeneration of the functional layer (101).

Cell identity, proliferation, regression and cell death of endometrial cells can be regulated by hormone nuclear receptors. Hormone nuclear receptors can interact with transcriptional corepressor complexes comprising histone deacetylases (Sin3A, HDAC1, HDAC2) and thus also with components of DNA methylation machinery to induce target gene repression (3). A gene identification study revealed approximately 140 genes (such as BTG3, FHL2, PMAIP1, $B T G 2, C D K N 1 A$ and $T G F B 2$ ) which are regulated by $17 \beta-$ oestradiol (E2) and involved in intracellular signalling cascades, cell proliferation and apoptosis (102). It is possible that mediators of hormone signalling and DNA methylation may crosstalk to regulate the methylation status of their target gene promoters, but it has been not directly confirmed, although it was shown that DNA promoter methylation of some steroid responsive genes can be maintained by the presence of circulating steroid hormones (2). Recent studies investigated changes in global DNA methylation levels during the normal menstrual cycle. A high level of methylated cytosines in cells of the stroma and glandular epithelium were observed in the proliferative phase of the menstrual cycle, whereas glandular cells of the epithelium were characterized by decreased levels of methylated cytosines during the secretory phase (4). Currently, it is known that deregulation of the DNA methylation pattern proceeds from different expression of DNMTs during the menstrual cycle. Some scientific studies confirmed that DNMT expression and function can also be regulated by steroid hormones, but molecular mechanisms are still poorly understood.

It was shown that DNMT1 and DNMT3A expression levels were decreased in the secretory phase compared to the proliferative phase, with the lowest level in the mid-secretory phase. Their levels were correlated with oestrogen levels (5) (Figure 3). A study by Vincent et al. also reported that expression of DNMT3A and DNMT3B is significantly lower in the secretory phase than in the proliferative phase (6). Similar results were observed in a study by Zelenko et al. They obtained results that DNMT1, DNMT3A and DNMT3B were significantly down-regulated in the midsecretory phase compared to the proliferative phase (3), although another study demonstrated different results compared with the previously mentioned studies and showed that the DNMT1 expression level was higher in the secretory phase than in the proliferative phase while DNMT3B expression levels were not changed in any phase (103). The reason for these discordant results in DNMT expression levels is unclear; probably, it could be due to different grouping of tissue samples or sources of endometrial samples. Changes in DNA methylation levels also correlate with steroid receptor levels. Ghabreau et al. showed that global DNA methylation status and also progesterone receptor level were significantly higher during the proliferative phase with a decrease towards the end of the secretory phase (4). These results indicate that changes in DNA methylation pattern are related to changes in DNMT expression levels that are under the control of ovarian steroid hormones and their nuclear receptors. It is obvious that DNA methylation plays a key role in the regulation of genes 


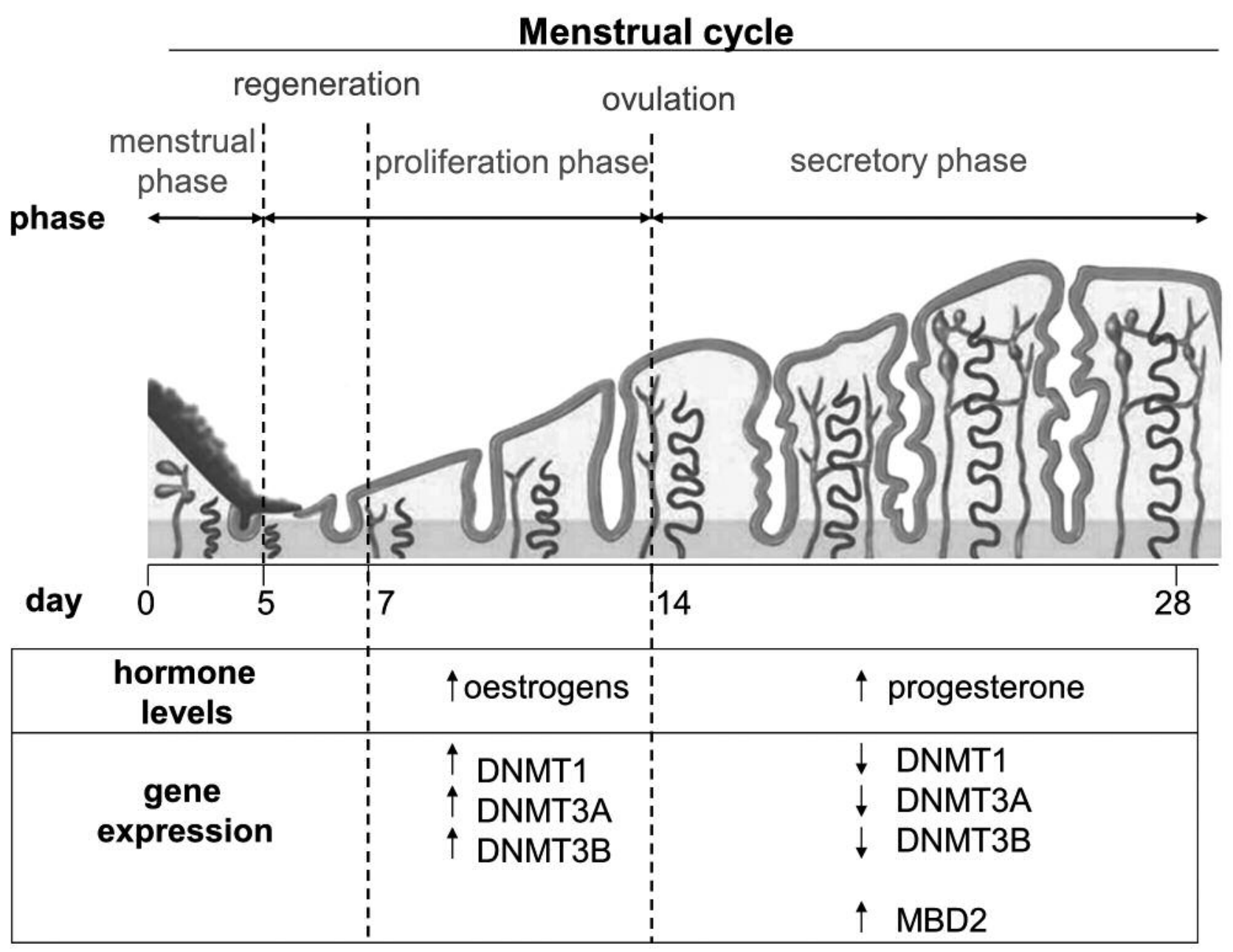

Figure 3. Menstrual cycle phases associated with gene expression changes of DNA methylation machinery proteins. DNMT: DNA methyltransferases; MBD2: DNA methyl-binding protein 2.

involved in cell growth and proliferation during the normal menstrual cycle.

There have been few scientific studies which showed changes in other genes coding proteins of DNA methylation machinery. The important component of DNA methylation machinery is the MBD family of proteins, which establish crosstalk between DNA methylation and histone modifications in gene silencing. These proteins may play a key role in gene regulation during the normal menstrual cycle, but their function in different endometrial phases during the normal menstrual cycle is not wellknown. So far, it has been demonstrated that MBD2 expression is higher in the secretory phase of the endometrium compared to the proliferative and menstrual phases, but there were no significant differences in MBD1 and $\mathrm{MeCP} 2$ expression throughout the normal menstrual cycle (103). Despite the important functions of these proteins in gene regulation during menstrual phases, there is missing information about gene expression changes of other proteins associated with DNA methylation machinery mentioned above.

\section{DNA methylation in endometrial cancer}

Components of DNA methylation machinery must be tightly regulated during the normal menstrual cycle to precisely influence endometrial cell proliferation and death. Deregulation of DNA methylation proteins can thus disrupt cell homeostasis of the endometrium. There is increased evidence that an aberrant DNA methylation pattern can result in various pathological forms of the endometrium (104) and in endometrial cancer development (105). 
Table I. Apoptosis-associated genes with aberrant DNA methylation in endometrial cancer.

\begin{tabular}{lccc}
\hline Gene & Alternate gene name & Methylation locations & Reference \\
\hline Hypermethylated genes in endometrial carcinoma & & & 118 \\
APC & Adenomatous Polyposis Coli & Promoter & $113,114,115,116$ \\
RASSF1 & Ras Association Domain Family Member 1 & Promoter & 119,120 \\
PTEN & Phosphatase And Tensin Homolog & Promoter & 124 \\
Hypomethylated genes in endometrial carcinoma & Caspase 8 & Promoter \\
CASP8 & & \\
\hline
\end{tabular}

Similar to other types of cancer, endometrial cancer cells acquire two main types of aberrant DNA methylation pattern during malignant transformation: global DNA demethylation/ hypomethylation and local DNA hypermethylation. DNA hypomethylation can occur in normally methylated DNA sequences including repetitive regions, intergenic as well as intragenic regions, and leads to microsatellite instability and upregulation of many genes, especially oncogenes, whereas DNA hypermethylation of $\mathrm{CpG}$ islands is associated with the promoter regions of mainly tumour suppressor genes and can occur early in endometrial carcinogenesis. A number of methylation studies established a list of frequently hypermethylated tumour suppressor genes and hypomethylated oncogenes in endometrial cancer. So far, more than 50 hypermethylated tumour suppressor genes have been identified including the most famous genes: $M L H 1, P T E N, p 16, A P C$, $M G M T, R A S S F 1, P R$ and $C D H 1$. On the other hand, few publications have described hypomethylated oncogenes in endometrial cancer (such as BMP, CTCFL, PARP1, CASP8) $(15,105-108)$. Genes with aberrant DNA methylation are involved in various biological pathways such as cell adhesion, cell proliferation, signalling transduction, cell cycle regulation, microtubule stabilization and also apoptosis (105).

Apoptosis resistance and DNA methylation in apoptosisrelated genes. There are only very few scientific publications which demonstrate the aberrant DNA methylation status of apoptosis-related genes in endometrial cancer. DNA methylation changes in apoptosis-related genes can result in abnormal apoptosis regulation and apoptosis resistance development.

Apoptosis is a conserved process of programmed cell death which is important for maintaining a balance between cell death and cell proliferation, particularly in the normal menstrual cycle (109). It is activated in response to extrinsic or intrinsic death stimuli followed by the activation of caspases, a family of cysteine proteases that cleave regulatory and structural biomolecules and induce cell death. Apoptotic death is mediated mainly through two pathways: the extrinsic (death receptor pathway) and intrinsic (mitochondrial) pathways. The extrinsic pathway is activated by the ligation of death receptors of the tumour necrosis factor family and their death ligands. It results in the formation of a death-inducing signalling complex (DISC) and activation of initiator caspases which can directly cleave downstream effector caspases, culminating in cell death (110, 111). The intrinsic apoptosis pathway is activated by various stress-inducing signals resulting in mitochondrial membrane permeabilization and release of apoptogenic factors. It leads to the formation of a large cytosolic apoptosome complex and activation of the caspase cascade. The activation of apoptosis is tightly regulated by many positive and negative regulators, which are often abnormally regulated in cancer cells. An aberrant DNA methylation pattern can be one of the major mechanisms which promote the ability of cancer cells to evade apoptosis and thus contribute to therapeutic resistance $(15,111)$.

Evading apoptosis is one of the most important physiological and biochemical hallmarks of cancer which contributes to unlimited cell proliferation and endometrial tumorigenesis (14). Apoptosis resistance to treatment is still a major problem in the successful treatment of endometrial cancer. Cancer cells have developed various mechanisms of apoptosis resistance. Wong demonstrated five important strategies which contribute to evasion of apoptosis including an impaired receptor signalling pathway, genetic mutations, reduced expression of caspases, increased expression of apoptotic inhibitors and disrupted balance of the Bcl-2 family of proteins, probably due to changes in DNA methylation pattern (109). In the following section we will mention methylated apoptotic genes, which can contribute to resistance to apoptosis (Table I).

The tumour suppressor gene RASSF1A (ras association domain family member 1 ), chromosome location $3 \mathrm{p} 21.3$, is known for inhibiting accumulation of cyclin D1 and for inducing cell cycle arrest. The protein RASSF1 can activate the apoptosis regulator Bax when it is associated with MOAP1 (modulator of apoptosis 1) and thus induce apoptosis (112). Promoter methylation of RASSF 1A was observed in up to $74 \%$ of endometrial carcinomas and was associated with reduced 
gene expression. Methylation in this gene is frequently observed in type I endometrioid recurrent carcinomas and correlates with poor prognosis (113-116). Arafa et al. also observed RASSF 1A methylation in $50 \%$ of hyperplasia samples and they suggested that RASSF $1 A$ promoter methylation can be an early event in endometrial carcinogenesis (113).

Adenomatous Polyposis Coli $(A P C)$, another tumour suppressor gene on chromosome 5q22.2, is often methylated in endometrial carcinoma. The protein APC acts as a negative regulator of the Wnt signalling pathway, playing an important role in cell migration and microtubule stabilization, and can induce apoptosis through caspase 8 activation (117). Methylation of the $A P C$ gene promoter was observed in endometrial carcinomas and it occurs frequently in tumours with microsatellite instability (118).

Promoter hypermethylation of another tumour suppressor gene PTEN (Phosphatase And Tensin Homolog) was observed in $18-19 \%$ of sporadic endometrial cancers (119, 120) where it correlated with an advanced stage of disease (119). The gene PTEN, located on chromosome 10q23.31, encodes phosphatidylinositol-3,4,5-trisphosphate 3phosphatase with dual specificity for tyrosine and serine/threonine phosphate residues. This protein antagonizes the PI3 kinase/AKT signalling pathway and thereby regulates cell proliferation and inhibits cell migration and focal adhesion formation (121). The protein PTEN can also induce cell cycle arrest and apoptotic cell death through the PI3K/AKT pathway $(122,123)$.

In contrast with these studies of DNA hypermethylation, Sánchez-Vega et al. showed hypomethylation in a genomic region near the CASP 8 tumour suppressor promoter in endometrioid cancer compared with normal tissue (124). This gene is located at chromosome 2 q33.1 and encodes a cysteineaspartic acid protease (caspase) that plays an important role in cell apoptosis. The protein CASP8 is an initiator caspase that is directly activated by death receptors to proteolytically activate effector caspases in the execution phase of apoptosis. Methylation in this gene was correlated with higher gene expression as well as higher levels of histone marks (H3K4me3 and H3K27ac) which are associated with the promoters of actively transcribed genes. The authors suggested that CASP8 demethylation can restore gene expression and trigger cell death in cancer cells (124). The mechanism of CASP8 demethylation is unknown; possibly, it could be a consequence of global hypomethylation of the cancer genome.

\section{Conclusion}

Recent progress made in the field of epigenetics, especially the study of DNA methylation, has provided valuable evidence that DNA methylation machinery and its components can play a key role in gene regulation during the normal menstrual cycle. Recent studies showed that an aberrant DNA methylation profile results in various pathological forms of the endometrium and endometrial cancer development. It is, therefore, necessary to recognize differences between DNA methylation changes that occur naturally in the menstrual cycle phases and those in cancer cells. DNA methylation machinery is composed of many protein complexes to accurately regulate gene expression together with other epigenetic mechanisms, but there are many unanswered questions about the DNA methylation mechanism and its consequences for gene activity in various genomic regions. Nowadays, it is undoubted that aberrant DNA methylation disrupts the gene function of many key genes that decide cell fate. One group of them is genes associated with apoptotic cell death. The inability of cancer cells to respond to apoptotic stimuli is a major problem in successful anticancer therapy. Despite that, there are only a few studies dealing with the aberrant DNA methylation status of apoptosis-associated genes in endometrial cancer, and there is missing information about the epigenetic regulation of these genes. Knowledge of disrupted gene regulation in DNA methylation levels could be helpful to distinguish normal tissue from cancerous tissue. Furthermore, epigenetic modifications are easily reversible by pharmacologic intervention and therefore developing new anticancer compounds dedicated to inducing apoptosis could improve targeted anticancer therapy in endometrial cancer patients.

\section{Acknowledgements}

This work was supported by the Slovak Research and Development Agency under contract No. APVV-0224-12 by the ministry of Health of Slovac Republic under the project 2012/27-UKMA-4 and by the project "CREATING A NEW DIAGNOSTIC ALGORITHM FOR SELECTED CANCER DISEASES", ITMS code 26220220022 - co-financed from EU sources and European Regional Development Fund. The Authors would like to sincerely thank Proof-Reaging-Service.com for proof-reading this manuscript.

\section{References}

1 Aranda A and Pascual A: Nuclear hormone receptors and gene expression. Physiol Rev 81: 1269-1304, 2001.

2 Auger CJ, Coss D, Auger AP and Forbes-Lorman RM: Epigenetic control of vasopresis in expression is maintained by steroid hormones in the adult male rat brain. Proc Natl Acad Sci USA 108: 4242-4247, 2011.

3 Zelenko Z, Aghajanova L, Irwin JC and Giudice LC: Nuclear receptors, coregulator signaling, and chromatin remodeling pathways suggest involvement of the epigenome in the steroid hormone response of endometrium and abnormalities in endometriosis. Reprod Sci 19: 152-162, 2012.

4 Ghabreau L, Roux JP, Niveleau A, Fotaniere B, Mahe C, mokni $\mathrm{M}$ and Frappart L: Correlation between the DNA global methylation status and progesterone receptor expression in normal endometrium, endometrioid adenocarcinoma and precursors. Virchows Arch 445(2): 129-34, 2004. 
5 Yamagata Y, Asada H, Tamura I, Lee L, Maekawa R, Taniguchi K, Taketani T, Matsuoka A, Tamura $\mathrm{H}$ and Sugino N: DNA methyltransferase expression in the human endometrium: downregulation by progesterone and estrogen. Hum Reprod 24: 1126-1132, 2009.

6 Vincent ZL, Farguar CM, Mitchell MD and Ponnampalam AP: Expression and regulation of DNA methyltransferases in human endometrium. Fertil Steril 95(4): 1522-1525, 2011.

7 Munro SK, Farguar CM, Mitchell MD and Ponnampalam AP: Epigenetic regulation of endometrium during the menstrual cycle. Mol Hum Reprod 16: 297-310, 2010.

8 Ferlay J, Soerejomataram I, Dikshit R, Eser S, Mather C, Rebelo M, Parkin DM, Forman D and Bray F: Cancer incidence and mortality worldwide: Sources, methods and major patterns in GLOBOCAN. Int J Cancer 136(5): E359-386, 2012.

9 Plataniotis G, Castiglione M and EMSO Guidelines Working Group: Endometrial cancer: ESMO Clinical Practice Guidelines for Diagnosis, treatment and follow-up. Ann Oncol 21(5): 4145, 2010.

10 Llauradó M, Ruiz A, Majem B, Ertekin T, Colás E, Pedrola N, Devis L, Rigau M, Sequeiros T, Montes M, Garcia M, Cabrera S, Gil-Moreno A, Xercavins J, Castellví J, Garcia, A, Ramón y Cajal S, Moreno G, Alameda F, Vázquez-Levin M, Palacios J, Prat J, Doll A, Matías-Guiu X, Abal M and Reventós J: Molecular bases of endometrial cancer: new roles for new actors in the diagnosis and the therapy of the disease. Mol Cell Endocrinol 358(2): 244-255, 2012.

11 Matias-Guiu X, Catasus L, Bussaglia E, Lagarda H, Garcia A, Pons C, Munoz J, Argüelles R, Machin P and Prat: Molecular pathology of endometrial hyperplasia and carcinoma. Hum Pathol 32(6): 569-577, 2001.

12 Yeramian A, Moreno-Bueno G, Dolcet X, Catasus L, Abal M, Colas E, Reventos J, Palacios J, Prat J and Matias-Guiu X: Endometrial carcinoma: molecular alterations involved in tumor development and progression. Oncogene 32(4): 403-413, 2013.

13 Chaudhry P and Asselin E: Resistance to chemotherapy and hormone therapy in endometrial cancer. Endocr Relat Cancer 16(2): 363-380, 2009.

14 Hanahan D and Weinberg RA: Hallmarks of cancer: the cancer generation. Cell 144(5): 646-674, 2011.

15 Hervouet E, Cheray M, Vallette FM and Cartron PF: DNA Methylation and Apoptosis Resistance in Cancer Cells. Cell 2(3): 545-573, 2013.

16 Sharma S, Kelly TK and Jones PA: Epigenetics in cancer. Carcinogenesis 31(1): 27-36m, 2010.

17 Tao MH and Freudenheim JL: DNA methylation in endometrial cancer. Epigenetics 5(6): 491-498, 2010.

18 Waddington CH: The epigenotype. Endeavour 1: 18-20, 1942.

19 Holliday R: Epigenetics: a historical overview. Epigenetics 1(2): 76-810, 2006.

20 Nachajova M, Mersakova S, Sivakova J, Krivus S, Szepe P, Hatok J and Adamkov M: New molecular aspects of endometrial carcinoma. Neuro Endocrinol Lett 36(7): 638-643, 2015.

21 Ning X, Shi Z, Liu X, Zhang A, Han L, Jiang K, Kang C and Zhang Q: DNMT and EZH2 mediated methylation silences the micro RNA-200b/a/429 gene and promotes tumor progression. Cancer Lett 359(2): 198-205, 2015.

22 Hotchkiss RD: The quantitave separation of purines, pyrimidines, and nucleosides by paper chromatography. J Biol Chem 175: 315-332, 1948.
23 Holliday R and Pugh JE: DNA modification mechanisms and gene activity during dvelopment. Science 187: 226-232, 1975.

24 Lim DHK and Maher ER: DNA methylation: a form of epigenetic control of gene expression. The Obstetrician and Gynaecologist 12: 37-42, 2010

25 Breiling A and Lyko F: Epigenetic regulatory functions of DNA modifications: 5-methylcytosine and beyond. Epigenetics Chromatin 8: 24, 2015.

26 Pennings S, Allan J and Davey CS: DNA methylation, nucleosome formation and positioning. Brief Funct Genomic Proteomic 3(4): 351-361, 2005.

27 Ehrlich M: DNA hypomethylation in cancer cells. Epigenomics 1(2): 239-59, 2009.

28 Miranda TB and Jones PA: DNA methylation: the nuts and bolts of repression. J Cell Physiol 213(2): 384-390, 2007.

29 Estécio MR and Issa JP: Dissecting DNA hypermerhylation in cancer. FEBS Lett 585(13): 2078-2086, 2011.

30 Michaud EJ, van Vugt MJ, Bultman, SJ, Sweet HO, Davisson MT and Woychik RP: Differential expression of a new dominant agouti allele (Aiapy) is correlated with methylation state and is influenced by parental lineage. Genes dev 8: 1463$1472,1994$.

31 Ukai H, Ishii-Oba H, Ukai-Tadenuma M, Ogiu T and Tsuji H: Formation of an active form of the interleukin-2/15 receptor beta-chain by insertion of the intercisternal A particle in a radiation-induced mouse lymphoma and its role in tumorigenesis. Mol Carcinog 37: 110-119, 2003.

$32 \mathrm{Xia}$ J, Han L and Zhao Z: Investigating the relationship of DNA methylation with mutation rate and allele frequency in the human genome. BMC Genomics 8: S7, 2012.

33 Fienberg AP and Vogelstein B: Hypomethylation distinguishes genes of some human cancers from their normal couterparts. Nature 301(5895): 89-92, 1983.

34 Wahlfors J, Hiltunen, H, Heinonen K, Hamalainen E, Alhonen $\mathrm{L}$ and Janne J: Genomic hypomethylation in human chronic lymphocytic leukemia. Blood 80(8): 2074-2080, 1992.

35 Cheng P, Schmutte C, Cofer KF, Felix JC, Yu MC and Dubeau L: Alterations in DNA methylation are early, but not initial, events in ovarian tumorigenesis. Br J Cancer 75(3): 396-402, 1997.

36 Bedford MT and van Helden PD: Hypomethylation of DNA in pathological conditions of the human prostate. Cancer Res 47(20): 5274-5276, 1987.

37 Kim MJ, White-Cross JA, Shen L, Issa JP and Rashid A: Hypomethylation of long interspersed element-1 in hepatocellular carcinomas. Mod Pathol 22(3): 442-449, 2009.

38 Hoivik EA, Kusonmano K, Halle MK, Berg A, Wik E and Werner HMJ: Hypomethylation of the CTCFL/BORIS promoter and aberrant expression during endometrial cancer progression suggests a role as an Epi-driver gene. Oncotarget 5(4): 10521061, 2014.

39 Rhee YY, Lee TH, Song YS, Wen X, Kim H, Jheon S, Lee CHT, Kim J, Cho NY, Chung JH and Kang GH: Prognostic significance of promoter $\mathrm{CpG}$ island hypermethylation and repetitive DNA hypomethylation in stage I lung adenocarcinoma. Virchows Arch 466: 675-683, 2015.

40 Ghavifekr Fakhr M, Farshdousti M, Shanehbandi and Baradaran B: DNA methylation pattern as important epigenetic criterion in cancer. Genet Res Int 2013: 317569, 2013. 
41 Estécio MR, Gharibyan V, Shen L, Ibrahim AE, Doshi K, He R, Jelinek J, Yang AS, Yan, PS, Huang TH, Tajara EH and Issa JP: LINE-1 hypomethylation in cancer is highly variable and inversely correlated with microsatellite instability. PLoS One 2(5): e399, 2007.

42 Esteller M: Cancer epigenomics: DNA methylomes and histone-modifications maps. Nat Rev Genet 8(4): 286-296, 2007.

43 Wolff EM, Chihara Y, Pan F, Weisenberger DJ, Siegmund KD, Sugano K, Laird, PW, Jones PA and Liang G: Unique DNA methylation patterns distinguish noninvasive and invasive urothelial cancers and establish an epigenetic field defect in premalignant tissue. Cancer Res 70(20): 8169-8178, 2010.

44 Deaton AM and Bird A: CpG islands and the regulation of transcription. Genes Dev 25(10): 1010-1022, 2011.

45 Gardiner-Garden $\mathrm{M}$ and Frommer $\mathrm{M}$ : $\mathrm{CpG}$ islands in vertebrate genomes. J Mol Biol 196(2): 261-282, 1987.

46 Sharp Aj, Stathaki, E, Migliavacca E, Brachmakary M, Montgomery SB, Dupre $\mathrm{Y}$ and Antonarakis SE: DNA methylation profiles of human active and inactive $\mathrm{X}$ chromosomes. Genome Res 21(10): 1592-1600, 2011.

47 Moore LD, Le T and Fan G: DNA methylation and its basic function. Neuropsychopharmacology 38: 23-38, 2013.

48 Mohn, F, Weber M, Rebhan M, Roloff C, Richter J, Stadler MB, Bibel M and Schubeler D: Lineage-specific polycomb targets and de novo DNA methylation define restriction and potential of neuronal progenitors. Mol Cell 30: 755-766, 2008.

49 Meng H, Cao Y, Qin L, Song X, Zhang Q, Shi Y and Cao L: DNA methylation, its mediators and genome integrity. Int J Biol Sci 11(5): 604-617, 2015.

50 Simpkins SB, Bocker T, Swisher EM, Mutch DG, Gersell DJ, Kovatich AJ, Palazzi JP, Fishel R and Goodfellow PJ: MLH1 promoter methylation and gene silencing is the primary cause of microsatellite instability in sporadic endometrial cancers. Hum Mol Genet 8(4):661-666, 1999.

51 Parsons MT, Buchanan DD, Thompson B, Young JP and Spurdle AB: Correlation of tumour BRAF mutations and MLH1 methylation with germline mismatch repair (MMR) gene mutation status: a literature review assesing utility of tumor features for MMR variant classification. J Med Genet 49(3): 151-157, 2012

52 Maunakea AK, Nagarajan RP, Bilenky M, Ballinger TJ, D'Souza C, Fouse SH, Johnson BE, Hong CH, Nielsen C, Zhao Y, Turecki G, Delaney A, Varhol R, Thiessen N, Shchors K, Heine VM, Rowitch DH, Xing X, Fiore Ch, Schillebeeckx M, Jones SJM, Haussler D, Marra MA, Hirst M, Wang T and Costello JF: Conserved role of intragenic DNA methylation in regulating alernative promoters. Nature 466: 253-257, 2010.

53 Ball MP, Li JB, Gao Y, Lee JH, LeProust EM Park IH, Xie B, Daley GQ and Church GM: Targeted and genome-scale strategies reveal gene-body methylation signatures in human cells. Nat Biotechnol 27: 361-368, 2009.

54 Jones PA: The DNA methylation paradox. Trends Genet 15: 34 37, 1999.

55 Zhang B, Xing X, Li J, Lowdon RF, Zhou Y, Lin N, Zhang B, Soudaram V, Chiappinelli KB, Hagemann IS, Mutch DG, Goodfellow PJ and Wang T: Comparative DNA methylome analysis of endometrial carcinoma reveals complex and distinct deregulation of cancer promoters and enhancers. BMC Genomics 15: 868, 2014
56 Keller TE, Han P and Yi SV: Evolutionary Transition of Promoter and Gene Body DNA Methylation across InvertebrateVertebrate Boudary. Mol Biol Evol 33(4): 1019-1028, 2016.

57 Yang X, Han H, De Carcalho DD, Lay FD, Joneas PA and Liang G: Gene body methylation can alter gene expression and is a therapeutic target in cancer. Cancer Cell 26(4): 577-590, 2014.

58 Erlanson DA, Chen L and Verdine GL: DNA methylation through a locally unpaired intermediate. J Am Chem Soc 115(26): 12583-12584, 1993.

59 Klimsauksas S, Kumar S, Roberts RJ and Cheng X: HhaI methyltransferase flips its target base out of the DNA helix. Cell 76(2): 357-369, 1994.

60 Bestor, TH: The DNA methyltransferases of mammals. Hum Mol Genet 9(16): 2395-2402, 2000.

61 Siedlecki P, Zielenkiewicz P: Mammalian DNA methyltransferases. Acta Biochimica Polonica 53(2): 245-256, 2006.

62 Bestor T, Laudano A, Mattaliano R and Ingram V: Cloning and sequencing of a cDNA encoding DNA methyltransferases of mouse cells. The carboxyl-terminal domain of the mammalian enzymes is related to bacterial restcriction methyltransferases. J Mol Biol 203: 971-983, 1988.

63 Yoder JA, Soman NS, Verdien GL and Bestor TH: DNA (cytosine)-methyltransferases in mouse cells and tissues. Studies with a mechanism-based probe. J Mol Biol 270(3): 385395, 1997.

64 Kato, Y, Kaneda M, Hata K, Kumaki K, HIssano M, Kohara Y, Okano M, Li E, Nozaki M and Sasaki H: Role of the Dnmt3 family in de novo methylation of imprinted and repetitive sequences during male germ cell development in the mouse. Hum Mol Genet 16(19): 2272-2280, 2007.

65 Kaneda M, Okano m, Hata K, Sado T, Tsujimoto N, Li E and Sasaki H: Essential role for de novo DNA methyltransferase Dnmt3a in paternal and maternal imprinting. Nature 429(6994): 900-903, 2004.

66 Smallwood SA, Tomizawa S, Krueger F, Ruf N, Carli N, segons-Pichon A, Sato S, Hata K, Andrews SR and Kelsey G: Dynamic $\mathrm{CpG}$ islands methylation landscape in oocytes and preimplantation embryos. Nat Genet 43(8): 811-814, 2011.

67 Cheng X and Blumenthal RM: Mammalian DNA methyltransferases: a structural perspective. Structure 16(3): 341-350, 2008.

68 Chedin F, Liber MR and Hsieh CL: The DNA methyltransferase-like protein DNMT3L stimulates de novo methylation by Dnmt3a. Proc Natl Acad Sci USA 99(26): 16916-16921, 2002.

69 Hata K, Okano M, Lei H and Li E: Dnmt3L cooperates with Dnmt3 family of de novo DNA methyltransferases to establish maternal imprints in mice. Development 129(8): 1983-1993, 2002.

70 Shanmugam R, Fierer J, Kaiser S, Helm M, Jurkowski TP and Jeltsch A: Cytosine methylation of tRNA-Asp by DNMT2 has a role in translation of proteins containing poly-Asp sequences. Cell Discovery 1: 15011, 2015.

71 Bourc'his D, Xu GL, Lin CS, Bollman B and Bestor TH: Dnmt3L and the establishment of maternal genomic imprints. Science 294(5551): 2536-2539, 2001.

72 Dong S, Jeffrey A, Yoder and Cheng X: Structure of human DNMT2, an enigmatic DNA methyltransferase homolog that displays denaturant-resistant binding to DNA. Nucleic Acids Res 29: 439-448, 2001. 
73 Ehrlich M, DNA hypomethylation in cancer cells. Epigenomics 1: 239-259, 2009.

74 Rai K, Huggins IJ, James SR, Karpf AR, Jones DA, Cairns BR: DNA demethylation in zebrafish involves the coupling of a deaminase, a glycosylase, and gadd45. Cell 135(7): 1201-1212, 2008.

75 Tahiliani M, Koh KP, Shen Y, Pastor WA, Bandkuwala H, Brudno Y, Aqarwal S, Iyer LM, Aravind L and Rao L: Conversion of methylcytosine to 5-hydroxymethylcytosine in mammalian DNA by MLL partner TET1. Science 324(5929): 930-935, 2009.

76 Ito S, Shen L, Dai Q, Wu SC, Collins LB, Swenberg JA, He C and Zhang Y: Tet proteins can convert 5-methylcytosine to 5formylcytosine and 5-carboxylcytosine. Science 333(6047): 1300-1303, 2011.

77 Cortellino S, Xu J, Sannai M, Moore R, Caretti E, Cigliano A, Le Coz M, Devarajan K, Wessels A, Soprano D, Abramowitz LK, Bartolomei MS, Ranbow F, Bassi MR, Bruno T, Fanciulli M, Renner C, Klein-Szanto AJ, Matsumoto Y, Kobi D, Davidson I, Alberti C, Laue L and Bellacossa A: Thymine DNA glycosylase is essential for active DNA demethylation by linked deamination-base excision repair. Cell 146(1): 67-79, 2011.

78 Nan X, Nq HH, Johnson CA, Laherty CD, Turner BM, Eisenman RN and Bird A: Transcriptional repression by the methyl-CpG-binding protein $\mathrm{MeCP} 2$ involves a histone deacetylase complex. Nature 393(6683): 386-389, 1998.

79 Meehan RR, Lewis JD, McKay S, Kleiner EL and Bird AP: Indentification of a mammalian protein that binds specifically to DNA containing methylated CpGs. Cell 58(3): 499-507, 1989.

80 Lewis, JD, Meehan RR, Henzel WJ, Maurer-Fogy I, Jeppesen $\mathrm{P}$, Klein F and Bird A: Purification, sequence, and cellular localization of a novel chromosomal protein that binds to methylated DNA. Cell 69(6): 905-914, 1992.

81 Hedrich B, Hardeland U, Ng HH, Jiricny J and Bird A: The thymine glycosylase MBD4 can bind to the product of deamination at methylated Cpg sites. Nature 401(6750): 301304, 1999.

82 Hashimoto H, Horton JR, Zhang X and Cheng X: UHRF1, a modular multi-domain protein, regulates replication-coupled crosstalk between DNA methylation and histone modifications. Epigenetics 4(1): 8-14, 2009.

83 Sharif J, Muto M, Takebayashi S, Suetake I, Iwamatsu A, Endo TA, Shinga J, Mizutani-Koseki Y, Toyodo T, Okamura K, Tajima S, Mitsuya K, Okano M and Koseki H: The SRA protein Np95 mediates epigenetic inheritance by recruiting Dnmt1 to methylated DNA. Nature 450(7171): 908-912, 2007.

84 Arita k, Ariyoshi M, Tochio H, Nakamura Y and Shirakawa M: Recognition of hemi-methylated DNA by the SRA protein UHRF1 by a base-flipping mechanism. Nature 455(7214): 818 $821,2008$.

85 Achour M, Fuhrmann G, Alhosin m, Rondé P, Chataigneau T, Mousli M, Schini-Kerth VB and Bronner C: UHRF1 recruits the histone acetyltransferase Tip60 and controls its expression and activity. Biochemom Biophys Res Commun 390(3): 523$528,2009$.

86 Kim JK, Esteve PO, Jacobsen SE and Pradhan S: UHRF1 binds G9a and participates in p21 transcriptional regulation in mammalian cells. Nucleic Acids Res 37(2): 493-505, 2009.

87 Pichler G, Wolf P, Schmidt CS, Meilinger D, Schneider K, Frauer C, Fellinger K, Rottach A and Leonhardt H: Cooperative
DNA and histone binding by Uhrf2 links the two major repressive epigenetic pathways. J Cell Biochem 112(9): 2585$2593,2011$.

88 Daniel JM, Spring CM, Crawford HC, Reynolds AB and Baig A: The p120(ctn)-binding partner Kaiso is a bimodal DNAbinding protein that recognizes both a sequence-specific consensus and methylated $\mathrm{CpG}$ dinculeotides. Nucleic Acids Res 30(13): 2911-2919, 2002.

89 Filion GJ, Zhenilo S, Salozhin S, Yamada D, Prokhortchouk E and Defossez PA: A family of human zing finger proteins that bind methylated DNA and repress transcription. Mol Cell Biol 26(1): 169-181, 2006.

90 Cheung HH, Lee TL, Davis AJ, Taft DH, Rennert OM and Chan WY: Genome-wide DNA methylation profiling reveals novel epigenetically regulated genes and non-coding RNAs in human testicular cancer. Br J Cancer 102(2): 419-427, 2010.

91 Esteller M: Cancer epigenomics: DNA methylomes and histone-modifications maps. Nat Rev Genet 8(4): 286-296, 2007.

92 Fuks F, Hurd PJ, Wolf D, Nan X, Bird AP and Kouzarides T: The methyl-CpG-binding protein $\mathrm{MeCP} 2$ links DNA methylation to histone methylation. J Biol Chem 278(6): 40354040, 2003.

93 Smallwood A, Esteve PO and Carey M: Functional cooperation between HP1 and DNMT1 mediates gene silencing. Genes 21: 1169-1178, 2007.

94 Sadakierska-Chudy A, Kostrzewa RM and Filip M: A comprehensive view of the epigenetic landscape part I: DNA methylation, passive and active DNA demethylation pathways and histone variants. Neurotox Res 27(1): 84-97, 2015.

95 Viré, E, Brenner C, Deplus R, Blanchon L, Fraga M, Didelot C, Morey L, Van Eynde A, Bernard D, Vanderwinden JM, Bollen M, Esteller, M, Croce L, de Launoit $\mathrm{Y}$ and Fuks F: The Polycomb group protein EZH2 directly controls DNA methylation. Nature 439(7078): 871-874, 2006.

96 Fuks F: DNA methylation and histone modifications: teaming up to silence genes. Curr Opin Genet Dev 15(5): 490-495, 2005.

$97 \mathrm{Wu} \mathrm{H}$ and Zhang Y: Mechanisms and functions of Tet proteinmediated 5-methylcytosine oxidation. Genes Dev 25(23): 24362452, 2011.

98 Sivridis E and Giatromanolaki A: New insights into the normal menstrual cycle-regulatory molecules. Histol Histopathol 19: 511-516, 2004.

99 Baca-Garcia E, Sanchez-Gonzales A, Gonzales-Diaz-Corralero P, Gonzales Garcia I and de Leon J: Menstrual cycle and profiles of suicidal behaviour. Acta Psychiatr Scand 97: 32-35, 1998.

100 Lessey BA, Killam AP, Metzger DA, Haney AF, Greene GL and McCarty KS Jr: J Clin Endocrinol Metab 67(2): 334-340, 1988.

101 Padykula HA: Regeneration in the primate uterus: the role of stem cells. Ann N Y Acad Sci 622: 47-56, 1991.

102 Putnik M, Zhao C, Gustafsson JA and Dahlman-Wright K: Global indentification of genes regulated by estrogen signaling and demethylation in MCF-7 breast cancer cells. Biochem Biophys Res Commun 426(1): 26-32, 2012.

103 van Kaam KJ, Delvoux B, Romano A, D'Hooghe T, Dunselman GA and Groothuis PG: Deoxyribonucleic acid methyltransferase and methyl-CpG-binding domain proteins in human endometrium and endometriosis. Fertil Steril 95(4): 1421-1427, 2011. 
104 Guo SW: Epigenetics of endometriosis. Mol Hum Reprod 15(10): 587-607, 2009.

$105 \mathrm{Ma}$ X and Gao X: Epigenetic Modifications and Carcinogenesis of Human Endometrial Cancer. Austin J Clin Pathol 1(3): 1014, 2014.

106 Tao MH and Freudenheim JL: DNA methylation in endometrial cancer. Epigenetics 5(6): 491-498, 2010.

107 Visnovsky J, Fiolka R, Kudela E, Slavik P, Krkoska M, Lasabova $\mathrm{Z}$ and Danko J: Hypermethylation of selected genes in endometrial carcinogenesis. Neuro Endocrinol Lett 34(7): 675$680,2013$.

108 Kajo K, Vallová M, Biró C, Bognár G, Macháleková K, Závodná K, Galbavý S and Zúbor P: Molecular pathology of endometrial carcinoma - a review. Cesk Patol 51(2): 65-73, 2015.

109 Wong RS: Apoptosis in cancer: from pathogenesis to treatment. J Exp Clin Cancer Res 30: 87, 2011.

110 Kischkel FC, Hellbardt S, Behrmann I, Germer M, Pawlita M, Krammer PH and Peter ME: Cytotoxicity-dependent APO-1 (Fas/CD95)-associated proteins form a death-inducing signaling complex (DISC) with the receptor. EMBO J 14(22): 45579-5588, 1995.

111 Fulda S: Tumor resistance to apoptosis. Int J Cancer 124(3): 511515, 2009.

112 Baksh S, Tommasi F, Fenton S, Yu VC, Martins LM, Pfeifer GP, Latif F, Downward and Neel BG: The tumor suppressor RASSF1 and MAPK-1 link death receptor signaling to Bax conformational change and cell death. Mol Cell 18(6): 637-650, 2005.

113 Arafa M, Kridelka F, Mathias V, Vanbellinghem JF, Renard I, Foidart JM, Boniver $\mathrm{J}$ and Delvenne P: High frequency of RASSF1 and RARb2 gene promoter methylation in morphologically normal endometrium adjacent to endometrioid adenocarcinoma. Histopathology 53(5): 525-532, 2008.

114 Liao X, Siu MK, Chan KY, Wong ES, Ngan HY, Chan QK, Li AS, Khoo US and Cheung AN: Hypermethylation of RAS effector related genes and DNA methyltransferase 1 expression in endometrial carcinogenesis. Int J Cancer 123(2): 296-302, 2008.

115 Pallarés J, Velasco A, Eritja N, Santacano M, Dolcet X, Cuatrecasas M, Palomar-Asenjo V, Catasús L, Prat J and MatiasGuiu X: Promoter hypermethylation and reduced expression of RASSF1 are frequent molecular alterations of endometrial carcinoma. Mod Pathol 21(6): 691-699, 2008.
116 Fiolka R, Zubor P, Janusicova V, Visnovsky J, Mendelova A, Kajo K, Lasabova Z, Plank L and Danko J: Promoter hypermethylation of the tumor-supressor genes RASSF1A, GSTP1 and CDH1 in endometrial cancer. Oncol Rep 30(6): 2878-2886, 2013.

117 Steigerwald K, Behbehani GK, Combs KA, Barton MC and Groden J: The APC tumor supressor promotes transcriptionindependent apoptosis in vitro. Mol Cancer Res 3(2): 78-89, 2005.

118 Zysman M, Saka A, Millar A, Knight J, Chapman W and Bapat B: Methylation of adenomatous polyposis coli in endometrial cancer occurs more frequently in tumors with microsatellite instability phenotype. Cancer Res 62(13): 3663-3666, 2002.

119 Salvesen HB, MacDonald N, Ryan A, Jacobs IJ, Lynch ED, Akslen LA and Das S: PTEN methylation is associated with advanced stage and mircosatellite instability in endometrial carcinoma. Ont J Cancer 91(1): 22-26, 2001.

120 Salvesen HB, Stefansson I, Kretzschmar EI, Gruber P, MacDonald ND, Ryan A, Jacobs IJ, Akslen LA and Das S: Significance of PTEN alterations in endometrial carcinoma: a population-based study of mutations, promoter methylation and PTEN protein expression. Int J Oncol 25(6): 1615-1623, 2004.

121 Waite KA and Eng C: Protean PTEN: a form and function. Am J Hum Genet 70(4): 829-844, 2002.

122 Weng L, Brown J and Eng C: PTEN induces apoptosis and cell cycle arrest through phosphoinositol-3-kinase/Akt -dependent and -independent pathways. Hum Mol Genet 10(3): 237-242, 2001.

123 Saini MK and Sanyal SN: PTEN regulates apoptotic cell death through PI3-K/Akt/GSK3 $\beta$ signaling pathway in DHM induced early colon carcinogensesis in rat. Exp Mol Pathol 93(1): 135146, 2012.

124 Sánchez-Vega F, Gotea V, Petrykowska HM, Margolin G, Krivak TC, DeLoia JA, Bell DW and Elnitski L: Recurrent patterns of DNA methylation in the ZNF154, CASP8, and VHL promoters across a wide spectrum of solid epithelial tumors and cancer cell lines. Epigenetics 8(12): 1355-1372, 2013.

Received June 14, 2016 Revised July 6, 2016 Accepted July 11, 2016 